\title{
Article
}

\section{Bismuth Silver Oxysulfide for Photoconversion Applications: Structural and Optoelectronic Properties}

amal baqais, Antton Curutchet, Ahmed Ziani, Hassan Ait ahsaine, Philippe Sautet, Kazuhiro Takanabe, and Tangui Le Bahers

Chem. Mater., Just Accepted Manuscript • DOI: 10.1021/acs.chemmater.7b02664 • Publication Date (Web): 18 Sep 2017

Downloaded from http://pubs.acs.org on September 25, 2017

\section{Just Accepted}

"Just Accepted" manuscripts have been peer-reviewed and accepted for publication. They are posted online prior to technical editing, formatting for publication and author proofing. The American Chemical Society provides "Just Accepted" as a free service to the research community to expedite the dissemination of scientific material as soon as possible after acceptance. "Just Accepted" manuscripts appear in full in PDF format accompanied by an HTML abstract. "Just Accepted" manuscripts have been fully peer reviewed, but should not be considered the official version of record. They are accessible to all readers and citable by the Digital Object Identifier (DOI®). "Just Accepted" is an optional service offered to authors. Therefore, the "Just Accepted" Web site may not include all articles that will be published in the journal. After a manuscript is technically edited and formatted, it will be removed from the "Just Accepted" Web site and published as an ASAP article. Note that technical editing may introduce minor changes to the manuscript text and/or graphics which could affect content, and all legal disclaimers and ethical guidelines that apply to the journal pertain. ACS cannot be held responsible for errors or consequences arising from the use of information contained in these "Just Accepted" manuscripts. 


\title{
Bismuth Silver Oxysulfide for Photoconversion Applications: Structural and Optoelectronic Properties
}

\author{
Amal BaQais, ${ }^{\mathrm{a}, \mathrm{b}}$ Antton Curutchet, ${ }^{\mathrm{c}}$ Ahmed Ziani, ${ }^{\mathrm{a}}$ Hassan Ait Ahsaine, ${ }^{\mathrm{a}}$ Philippe Sautet, ${ }^{\mathrm{d}, \mathrm{e}}$ Kazuhiro \\ Takanabe, ${ }^{\mathrm{a}, *}$ Tangui Le Bahers ${ }^{\mathrm{c}, *}$ \\ ${ }^{a}$ King Abdullah University of Science and Technology (KAUST), KAUST Catalysis Center (KCC) and Physical Sciences \\ and Engineering Division (PSE), 4700 KAUST, Thuwal, 23955-6900, Saudi Arabia. \\ ${ }^{\text {b} P r i n c e s s ~ N o u r a h ~ b i n t ~ A b d u l r a h m a n ~ U n i v e r s i t y ~(P N U), ~ C o l l e g e ~ o f ~ S c i e n c e s, ~ D e p a r t m e n t ~ o f ~ C h e m i s t r y, ~ R i y a d h, ~ 11671, ~ S a u d i ~}$ \\ Arabia. \\ ${ }^{c}$ Univ Lyon, ENS de Lyon, CNRS, Université Claude Bernard Lyon 1, Laboratoire de Chimie UMR 5182, F-69342, Lyon, \\ France. \\ ${ }^{\mathrm{d} D e p a r t m e n t ~ o f ~ C h e m i c a l ~ a n d ~ B i o m o l e c u l a r ~ E n g i n e e r i n g, ~ U n i v e r s i t y ~ o f ~ C a l i f o r n i a ~ L o s ~ A n g e l e s ~(U C L A), ~ L o s ~ A n g e l e s, ~ C A ~}$ \\ 90095, United States. \\ ${ }^{\mathrm{e}}$ Department of Chemistry and Biochemistry, University of California Los Angeles, Los Angeles, CA 90095, United States
}

\begin{abstract}
Single-phase bismuth silver oxysulfide, BiAgOS, was prepared by a hydrothermal method. Its structural, morphological and optoelectronic properties were investigated and compared with bismuth copper oxysulfide (BiCuOS). Rietveld refinement of the powder X-ray diffraction (XRD) measurements revealed that the BiAgOS and BiCuOS crystals have the same structure as $\mathrm{ZrSiCuAs}$ : the tetragonal space group P4/nmm. X-ray photoelectron spectroscopy (XPS) analyses confirmed that the BiAgOS has a high purity, in contrast with $\mathrm{BiCuOS}$, which tends to have $\mathrm{Cu}$ vacancies. The $\mathrm{Ag}$ has a monovalent oxidation state, whereas $\mathrm{Cu}$ is present in the oxidation states of +1 and +2 in the BiCuOS system. Combined with experimental measurements, density functional theory calculations employing the range-separated hybrid HSE06 exchange-correlation functional with spin-orbit coupling quantitatively elucidated photophysical properties such as absorption coefficients, effective masses and dielectric constants. BiCuOS and BiAgOS were found to have indirect bandgaps of 1.1 and $1.5 \mathrm{eV}$, respectively. Both possess high dielectric constants and low electron and hole effective masses. Therefore, these materials are expected to have high exciton dissociation capabilities and excellent carrier diffusion properties. This study reveals that BiAgOS is a promising candidate for photoconversion applications.
\end{abstract}

\section{INTRODUCTION}

Technologies dedicated to the light conversion, such as photovoltaic or photocatalysis, frequently involve a semiconductor. The need to develop these devices is a powerful driving force for developing new semiconductors family. For instance, photocatalytic water splitting is one of the most important reactions currently being investigated because it generates sustainable $\mathrm{H}_{2}$ fuel, which may originate from abundant solar energy. ${ }^{1-2}$ The heterogeneous photocatalysts are made of semiconductors that absorb sunlight, on the surface of which are generally deposited electrocatalysts that facilitate surface redox reactions. ${ }^{3-8}$ Recent efforts on the synthesis and characterization of suitable semiconductors led to the development of several material families, including oxynitrides, ${ }^{9-10}$ oxysulfides $^{11-12}$ and carbonitrides, ${ }^{12-14}$ for water splitting. Despite the efforts devoted to this research, the maximum photoconversion efficiency obtained experimentally is still far from the ideal one predicted by thermodynamics. ${ }^{15-16}$ Thus, the development of new semiconductors is still an important field of research.
In this context, $\mathrm{BiCuOX}(\mathrm{X}=\mathrm{S}, \mathrm{Se}$ and $\mathrm{Te})$ semiconductors belong to a family that has attracted great interest because of their optical, dielectric and electronic properties. ${ }^{17-23}$ Their crystal structures belong to the $\mathrm{P} 4 / \mathrm{nmm}$ space group, corresponding to the $\mathrm{ZrSiCuAs}$ crystal type, and are characterized by $\left[\mathrm{Bi}_{2} \mathrm{O}_{2}\right]$ and $\left[\mathrm{Cu}_{2} \mathrm{X}_{2}\right]$ layers perpendicular to the $c$ axis (Figure 1). In this structure, $\mathrm{Bi}$ is a trivalent ion 8-fold coordinated and $\mathrm{Cu}$ is a monovalent cation surrounded by a tetrahedron of sulfur atoms.

The low bandgaps of the selenide $\left(\mathrm{E}_{\mathrm{g}}=0.8 \mathrm{eV}\right)^{17,24}$ and telluride $\left(\mathrm{E}_{\mathrm{g}} \sim 0.5 \mathrm{eV}\right)^{17}$ representatives of this family were the reason they attracted attention for thermoelectric applications. In contrast, with a bandgap of approximately $1.2 \mathrm{eV}, \mathrm{BiCuOS}$ was considered for photovoltaic applications. For photocatalytic applications, in order to achieve useful redox reactions, these bandgaps are often too small for a one semiconductor based device, necessitating the use of specific architecture like tandem cell or Z-scheme strategy, combined to another semiconductor. ${ }^{15,25}$ Nevertheless, all the other electronic and dielectric properties associated with photoconversion (effective masses, exciton binding energy, dielectric constant, etc.) are suitable for photocatalytic applications. Thus, we attempted to 
perform bandgap engineering on $\mathrm{BiCuOS}$ by a judicious chemical substitution, the product of which could be directly used for photocatalytic applications. Two strategies can be considered for bandgap tuning, i.e., increasing the conduction band energy or decreasing the valence band energy. Recently, our DFT calculations proved that the $\mathrm{BiCuOS}$ conduction band potential, mainly constituted by $\mathrm{Bi} 6 \mathrm{p}$ orbitals, could be positioned more negatively by creating a solid solution with a rare earth element (such as La). ${ }^{26}$ However, no useful method for valence band tuning has been revealed. Knowing that the valence band of $\mathrm{BiCuOS}$ is made of a combination of $\mathrm{S} 3 \mathrm{p}$ orbitals and $\mathrm{Cu} 3 \mathrm{~d}$ orbitals, substituting $\mathrm{Cu}$ with other elements could change the valence band position.

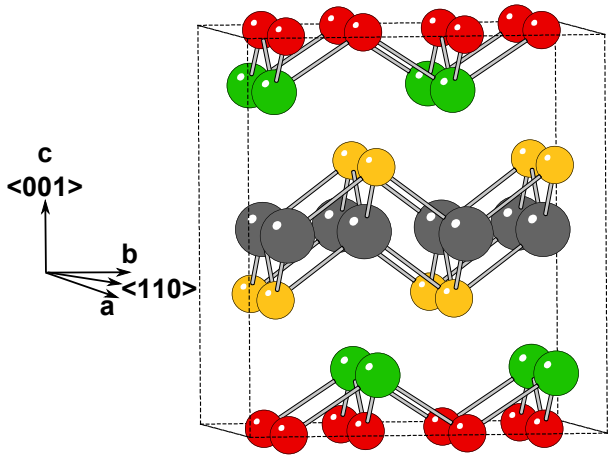

Figure 1. BiCuOS crystal structure $(2 \times 2 \times 1$ supercell) where green, gray, yellow and red atoms are $\mathrm{Bi}, \mathrm{Cu}, \mathrm{S}$ and $\mathrm{O}$, respectively. Only $\mathrm{Bi}-\mathrm{O}$ and $\mathrm{Cu}-\mathrm{S}$ bonds are drawn for clarity.

In this work, we investigate the total substitution of $\mathrm{Cu}$ with Ag to obtain BiAgOS because we expect this isovalent substitution to preserve the semiconducting nature of the original material with its favorable electronic and dielectric properties. Because the Ag 4d orbitals are lower in energy than the $\mathrm{Cu} 3 \mathrm{~d}$ orbitals, this substitution could potentially lead to a larger bandgap material. This study addresses how the complete substitution of $\mathrm{Cu}$ with $\mathrm{Ag}$ in $\mathrm{BiCuOS}$ affects its electronic structure using both experimental and theoretical characterizations. This joined experimental and theoretical procedure leads to the full characterization of the semiconductors for photoconversion applications and has already been applied to several semiconductors, including $\mathrm{SrTaO}_{2} \mathrm{~N},{ }^{27} \mathrm{C}_{3} \mathrm{~N}_{4},{ }^{14}$ and $\mathrm{CuGaS}_{2}{ }^{28}$ The optical, electronic and dielectric properties of $\mathrm{BiCuOS}$ and BiAgOS are compared. This report discusses their crystal structures, electronic structures, absorption coefficients, dielectric properties, effective masses, and potential photocatalytic activities.

\section{METHODOLOGY}

\subsection{Synthesis of BiCuOS and BiAgOS.}

$\mathrm{BiCuOS}$ and BiAgOS were synthesized using the hydrothermal protocol proposed by Sheets et al. ${ }^{21} \mathrm{Bi}_{2} \mathrm{O}_{3}$ and $\mathrm{Cu}_{2} \mathrm{O}$ ( or $\mathrm{Ag}_{2} \mathrm{O}$ ) were the oxide precursors. Sodium sulfide was used as the sulfur source. Stoichiometric amounts $(0.92 \mathrm{mmol}$, Aldrich $99.99 \%$ ) of the oxide precursors were thoroughly ground in an agate mortar for $15 \mathrm{~min}$ then $1.84 \mathrm{mmol}$ of $\mathrm{Na}_{2} \mathrm{~S} \cdot 9 \mathrm{H}_{2} \mathrm{O}$ (Strem 98\%) was added to the mixture. This mixture was transferred into a $100 \mathrm{~mL}$ poly(tetrafluoroethylene)lined pressure vessel (Parr Instruments), which was filled with $70 \mathrm{~mL}$ of Milli-Q water. The pressure vessel was sealed and heated to $248^{\circ} \mathrm{C}$ for $17 \mathrm{~h}$ for $\mathrm{BiCuOS}$ and $240{ }^{\circ} \mathrm{C}$ for $12 \mathrm{~h}$ for BiAgOS with a heating rate of $2{ }^{\circ} \mathrm{C} \mathrm{min}{ }^{-1}$. The precipitated solid products were recovered by filtration, followed by rins- ing three times with Milli-Q water. The recovered powder was dried overnight at $60{ }^{\circ} \mathrm{C}$, and the mass yield of the recovered powder was calculated based on the Bi content.

\subsection{Characterizations}

$X$-ray diffraction $(X R D)$. The powder XRD patterns were collected on a Bruker D8 Advanced A25 diffractometer equipped with a $\mathrm{Cu} X$-ray tube $\left(\mathrm{Cu}-\mathrm{K}_{\alpha} ; \lambda=0.154 \mathrm{~nm}\right)$ operated at $40 \mathrm{kV}$ and $40 \mathrm{~mA}$ in the Bragg-Brentano geometry using a linear position-sensitive detector with an opening of $2.9^{\circ}$. The diffractometer was configured with a $0.44^{\circ}$ divergence slit, a $2.9^{\circ}$ antiscatter slit, and $2.5^{\circ}$ Soller slits. A nickel filter was used to attenuate the contributions from the $\mathrm{Cu}-$ $\mathrm{K}_{\beta}$ fluorescence. The data sets were acquired over the $2 \theta$ range of $5-80^{\circ}$ with an integration step size of $0.01^{\circ}$, resulting in a counting time of $0.50 \mathrm{~s}$ per step. The Rietveld analysis was performed with the Fullprof program (v6.00).

Inductively coupled plasma optical emission spectrometry $(I C P-O E S)$. The stoichiometric molar ratios of BiAgOS and BiCuOS were determined by ICP-OES using a Varian 720-ES. Prior to the analysis, a known amount of the material was digested by microwave radiation in $5 \mathrm{~mL}$ of concentrated $(70 \%)$ nitric acid using $1000 \mathrm{~W}$ power and a high temperature $\left(220{ }^{\circ} \mathrm{C}\right)$ for $20 \mathrm{~min}$ in an ETHOS 1 microwave digestion system from Milestone. The solution was subsequently diluted with Milli-Q water to 25 or $50 \mathrm{~mL}$ before the ICP-OES analysis.

Scanning electron microscopy (SEM) and transmission electron microscopy (TEM) imaging. The size and morphology of the particles were studied by field emission SEM operating at $5 \mathrm{keV}$ on a Nova Nano 630 from FEI Company. The powders were directly pressed onto the SEM stub for analysis. Brightfield (BF)-TEM, selected area electron diffraction (SAED) and X-ray Energy Dispersive Spectroscopy (EDS) measurements were conducted using a Titan 80-300 CT transmission electron microscope equipped with a field emission gun with an accelerating voltage of $300 \mathrm{kV}$. Prior to the analysis, the samples were dispersed in acetonitrile and sonicated (at $144 \mathrm{~W}$ ) for $10 \mathrm{~min}$ in a bath at $35 \mathrm{kHz}$. A drop of the solution was put onto a Holey carbon film supported on a nickel-grid. The grid was dried in air prior to the TEM observations. The proper microscope settings and magnification range were selected to obtain the morphology and high-resolution (HR) TEM information. The interplanar d-spacings were obtained from both the SAED patterns and the Fast-Fourier Transform (FFT) of the HRTEM micrographs. Elemental mapping of all elements present in the samples was performed using a post-column energy filter (GIF Tridiem 863 from Gatan, Inc). The entire TEM analysis was performed using the Gatan Microscopy Suite (GMS v. 1.83) software package from Gatan, Inc.

$U V$-Vis spectroscopy. The optical properties were obtained via diffuse reflectance UV-Vis spectrometry. Diffuse reflectance data were collected using a JASCO model V-670 spectrophotometer along with an integrating sphere. The spectra were recorded over the range 300-1100 nm using halogen and deuterium lamps as the light sources. The reflectance data were transformed into absorption data $(\alpha / S)$ using the Kubelka-Munk transformation $f(\mathrm{R})=(\alpha / S)=(1-R)^{2} / 2 R$, where $\alpha$ was the absorption coefficient, $S$ was the scattering coefficient, and $R$ was the diffuse reflectance at a given photon energy. Assuming that the scattering coefficient is wavelength independent in the range considered, $f(\mathrm{R})$ becomes proportional to $\alpha$. The bandgap energy $\left(E_{\mathrm{g}}\right)$ was determined by Tauc plots 
from the intercept of a straight line tangential to the lowenergy region of a plot of $(f(R) . h v)^{I / 2}$ vs. $h v$ adapted for indirect bandgap semiconductors, where $h v$ was the energy of the incident photons.

BET measurement. $\mathrm{N}_{2}$ sorption studies were conducted using a Micromeritics ASAP 2420 to determine the BrunauerEmmett-Teller (BET) surface areas of the samples. Prior to the analysis, the samples were degassed overnight at $150{ }^{\circ} \mathrm{C}$ under vacuum.

Thermal gravimetric analysis (TGA) analysis. TGA was conducted with a Mettler-Toledo TGA/DSC1 Star system in the temperature range $30-750{ }^{\circ} \mathrm{C}$ in air and $\mathrm{N}_{2}$ atmosphere with a flow rate of $50 \mathrm{~mL} \mathrm{~min}^{-1}$ and a heating rate of $10^{\circ} \mathrm{C} \mathrm{min}{ }^{-1}$.

$X$-ray Photoelectron Spectroscopy (XPS). XPS studies were conducted with a Kratos Axis Supra spectrophotometer equipped with a monochromatic $\mathrm{Al} \mathrm{K} \alpha \mathrm{X}$-ray source $(h v=$ $1486.6 \mathrm{eV}$ ) operating at $150 \mathrm{~W}$, a multi-channel plate and delay line detector under a vacuum of $\sim 10^{-9}$ mbar. All the spectra were recorded using an aperture slot of $300 \mu \mathrm{m} \times 700$ $\mu \mathrm{m}$. The survey and high-resolution spectra were collected at fixed analyzer pass energies of 80 and $20 \mathrm{eV}$, respectively. Samples were mounted in a floating mode to avoid differential charging. Charge neutralization was required for all samples. Binding energies were referenced to the $\mathrm{C} 1 \mathrm{~s}$ binding energy of adventitious carbon contamination, set at $285.0 \mathrm{eV}$.

Mott-Schottky characterization. Electrochemical measurements were performed using a regular one-compartment electrochemical cell with a three-electrode configuration. A pellet of the material to analyze was used as working electrode. $\mathrm{Pt}$ wire and an $\mathrm{Ag} / \mathrm{AgCl}$ (saturated $\mathrm{KCl}$ ) electrode were used as counter and reference electrodes, respectively. The working electrodes were prepared by cold-pressing the powder into pellets $20 \mathrm{~mm}$ in diameter and $4 \mathrm{~mm}$ thick. The resulting pellets were sintered in an oven at $400{ }^{\circ} \mathrm{C}$ for $6 \mathrm{~h}$ under a nitrogen atmosphere. The pellet was mounted onto tantalum foil using silver paste to ensure a good contact and to avoid a Schottky contact between the pellet backside and the tantalum foil. A $0.2 \mathrm{M} \mathrm{Na}_{2} \mathrm{SO}_{4}$ solution ( $\mathrm{pH} 6$ ) was used as an electrolyte in all the electrochemical experiments. These experiments were performed using a 16-channel research-grade potentiostat system (VMP3), electrochemical interface and impedance analyzer from Bio-Logic Science Instruments. The potentials were recorded against the reference electrode, which was reported on the reversible hydrogen electrode (RHE) scale.

$$
E_{\mathrm{RHE}}=E_{\mathrm{Ag} / \mathrm{AgCl}}+0.198+0.059 \times \mathrm{pH}
$$

Electrochemical impedance spectroscopy was performed to estimate the flat band potential of the prepared electrode. Prior to the impedance spectroscopy, cyclic-voltammetry was conducted under Ar bubbling at a $10 \mathrm{mV} \mathrm{s}^{-1}$ scan rate to determine the potential window for the Mott-Schottky analysis, corresponding to a range of potentials with no electrochemical reaction in which the faradic current remains negligible. Impedance spectra were recorded at $1 \mathrm{kHz}$, and the amplitude of the superimposed sinusoidal potential signal was $5 \mathrm{mV}$ for each of the 70 steps under dark conditions.

Photoelectron emission spectroscopy in air (PESA). The valence band position was determined by PESA on a Riken Keiki AC-2 photoelectron spectrometer. The powders (approximately $50 \mathrm{mg}$ ) were dissolved in $50 \mathrm{~mL}$ of acetonitrile, sonicated for $5 \mathrm{~min}$ and then drop-cast on ITO substrates (2 $\mathrm{cm} \times 1 \mathrm{~cm}$ ) using a pipette. The standard hydrogen potential was calculated relative to the absolute vacuum potential. ${ }^{29}$

$$
E_{a b s}=E_{S H E}+4.44 \mathrm{~V}
$$

\subsection{Photocatalytic Reaction}

The photocatalytic reactions were performed in a recirculating batch reactor connected to a gas chromatography (GC) unit equipped with a vacuum line. ${ }^{30}$ The reactant solution was maintained at room temperature using a flow of cooling water during the reaction. Before irradiation, the reaction vessel was degassed several times to remove air, followed by the introduction of 100 Torr of Ar gas into the photocatalytic system. A Xe lamp (CERMAX PE300-BF, 300-W) was used as a light source, and the irradiation wavelength was controlled with a combination of a cold mirror and a water filter $(300<\lambda<800$ $\mathrm{nm})$. The homogeneity of the solution during the reaction was maintained by agitation with a magnetic stirrer. The gases evolved were analyzed by GC (Bruker 450 GC, TCD, Ar gas, molecular sieve 13X). The reactant solution was maintained at room temperature using a flow of cooling water during the reaction. Typically, $50 \mathrm{mg}$ of the powder sample was dispersed in $25 \mathrm{~mL}$ of $0.05 \mathrm{M} \mathrm{Na}_{2} \mathrm{~S}$ and $0.3 \mathrm{M} \mathrm{Na}_{2} \mathrm{SO}_{3}$ with 49.5 $\mu l$ of $0.1 \mathrm{M} \mathrm{RuCl}_{3} \cdot x \mathrm{H}_{2} \mathrm{O}$ solutions ( $1 \mathrm{wt} \% \mathrm{Ru}$ with respect to the catalyst used) and then sonicated for $15 \mathrm{~min}$ in an ultrasonic bath. This Ru solution was used as a source of Ru-cocatalyst that was photo-deposited during the reaction.

\subsection{Computational Details}

The computational details are identical to the ones used to compute the electronic properties of $\mathrm{BiCuOS}$ presented in the literature. ${ }^{31}$ For bulk semiconductors, geometry optimizations and frequency calculations were performed with the global hybrid functional $\mathrm{PBE}^{32}$ along with the ab initio CRYSTAL14 code $^{33,34}$ using localized (Gaussian) basis sets and solving self-consistently the Hartree-Fock and KohnSham equations to efficiently use the hybrid functionals. For the $\mathrm{O}, \mathrm{S}$ and $\mathrm{Cu}$ atoms, the all-electron triple zeta valence basis set $8-411 \mathrm{G}(\mathrm{d}),{ }^{35} 6-311 \mathrm{G}(\mathrm{d}),{ }^{36} 86-411 \mathrm{G}(2 \mathrm{~d}){ }^{37}$ were used, respectively. For the $\mathrm{Bi}$ atom, a modified version of the Hay and Wadt pseudopotential was used with the $31 \mathrm{G}(\mathrm{d})$ basis set for the valence electrons (5 valence electrons). ${ }^{38}$ For the $\mathrm{Ag}$ atom, the Hay and Wadt small core pseudopotential was used with the $311 \mathrm{G}(2 \mathrm{~d})$ basis set for the valence electrons (18 valence electrons). ${ }^{39}$ The reciprocal space was sampled with a $12 \times 12 \times 12 \mathrm{k}$-point mesh for both geometry optimization and vibrational calculations. The convergence criterion for the SCF cycle was fixed at $10^{-10} \mathrm{Ha}$ per unit cell for geometry optimization and frequencies calculations. The calculation of frequencies was performed within a harmonic approximation of the lattice potential, and the infrared intensities were obtained through the Berry Phase method. ${ }^{40}$ The vibrational contribution to the dielectric constant $\left(\varepsilon_{v i b}\right)$ was computed with PBE0 using CRYSTAL14 code.

All the electronic properties were computed using the HSE $06^{41,42}$ functional on the experimental geometries. To consider the relativistic effects involved with the bismuth atom, calculations of the electronic properties were performed with VASP $(5.2 \text { version })^{43-46}$ along with relativistic pseudopotentials and the non-collinear formalism ${ }^{47}$ to consider the spinorbit coupling, since CRYSTAL14 cannot handle this relativistic effect. For the dielectric constants and effective masses calculations, a $9 \times 9 \times 9$ k-point mesh was used, whereas a $12 \times 12 \times 12$ k-point mesh was used for the bandgap calcula- 
tions; both had a $400 \mathrm{eV}$ energy cutoff. The core electrons for each atom were described with the projector augmented plane wave (PAW) approach.

The band structure and the density of states were computed with the HSE06 functional using the CRYSTAL14 code with the same basis set used for the geometry optimizations. Atomic charges were computed using the Mulliken approach.

We used both PBE0 (for geometry optimization) and HSE06 (for electronic properties calculations) because of a benchmark on several semiconductors that some of us previously reported. ${ }^{23}$ This previous work showed that PBE0 gives a better match for the cell parameters than HSE06, while the latter functional is better suited for simulating electronic properties.

\section{RESULTS AND DISCUSSION}

3.1 Synthesis and structural characterizations.

The hydrothermal synthesis of $\mathrm{BiCuOS}$ as a reference sample was performed following the protocol developed by Sheets et al., which used $\mathrm{Bi}_{2} \mathrm{O}_{3}, \mathrm{Cu}_{2} \mathrm{O}$ and $\mathrm{Na}_{2} \mathrm{~S}$ precursors placed into MilliQ water. ${ }^{21}$ The temperature and reaction time (248 ${ }^{\circ} \mathrm{C}$ for $17 \mathrm{~h}$ ) were optimized to obtain a pure $\mathrm{BiCuOS}$ phase, and these optimized conditions were very close to those determined by Sheets et al. $\left(250{ }^{\circ} \mathrm{C}\right.$ for $\left.24 \mathrm{~h}\right)$. The high temperature was necessary both to solubilize the two starting oxides and to stabilize the $\mathrm{Cu}^{+}$ion that easily disproportionated into $\mathrm{Cu}^{0}$ and $\mathrm{Cu}^{2+}$. The main impurities observed for the lower synthesis temperatures were $\mathrm{BiCu}_{3} \mathrm{~S}_{3}$ and $\mathrm{Cu}_{2} \mathrm{~S}$. In the optimized conditions, the final yield was $\sim 81 \%$ by weight. The XRD pattern of the pure BiCuOS is shown in Figure 2 and agrees with those reported by Sheets et al. and Richard et al. (JCPDS 47-0277). ${ }^{19,21}$

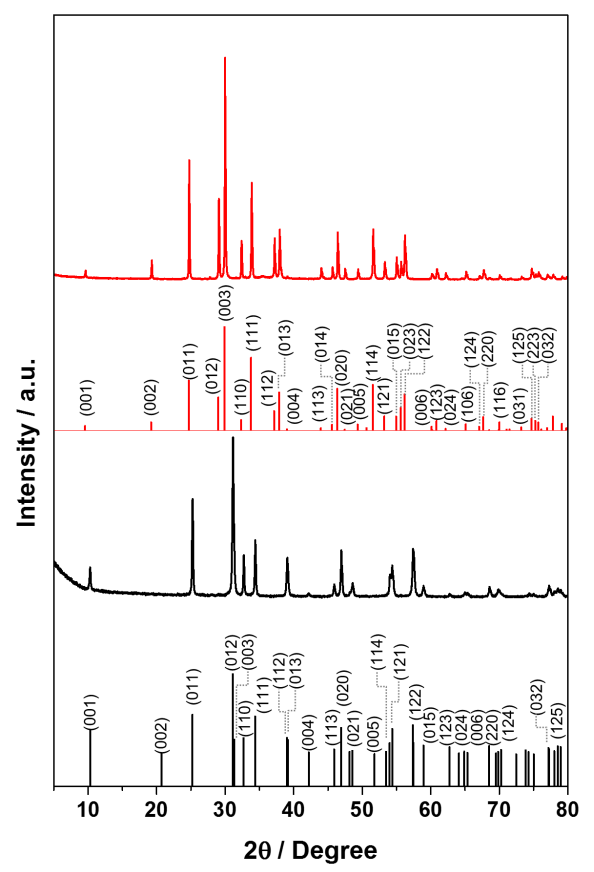

Figure 2. XRD patterns of $\mathrm{BiAgOS}$ (red) and $\mathrm{BiCuOS}$ (black) and their corresponding reference crystallographic information data.

BiAgOS was synthesized by adapting the BiCuOS synthesis procedure, replacing the $\mathrm{Cu}_{2} \mathrm{O}$ precursor with $\mathrm{Ag}_{2} \mathrm{O}$. The XRD pattern for the single phase BiAgOS powder is presented in Figure 2. No impurity phase is observed in the XRD pattern when the sample was synthesized at $240{ }^{\circ} \mathrm{C}$ for $12 \mathrm{~h}$, giving an $85 \%$ yield by weight. At lower reaction temperatures, the main impurities identified by XRD were $\mathrm{BiAgS}_{2}, \mathrm{Ag}_{2} \mathrm{~S}$ and $\mathrm{Bi}_{2} \mathrm{O}_{2} \mathrm{~S}$. The diffraction peak positions of $\mathrm{BiAgOS}$, relative to those of $\mathrm{BiCuOS}$, are shifted toward lower angles, indicating an increase in the cell parameters. Based on another synthesis protocol developed for this family of materials, like for $\mathrm{CeAgOS},{ }^{48}$ we attempted to synthesize the material in an evacuated sealed-fused silica tube from $\mathrm{Bi}_{2} \mathrm{O}_{3}, \mathrm{Ag}_{2} \mathrm{O}$ and $\mathrm{S}$ at $900{ }^{\circ} \mathrm{C}$ for $14 \mathrm{~h}$. The obtained material, however, contained a lot of impurity phases, such as $\mathrm{Ag}$ metal, $\mathrm{Bi}$ metal, $\mathrm{Bi}_{2} \mathrm{O}_{3}$ and $\mathrm{AgBiS}_{2}$ etc., confirming the effectiveness of hydrothermal synthesis protocol reported in this study.

Crystal structure refinement with the Rietveld method (see Supporting Information Figure S1) confirms that BiAgOS has the same crystal structure as BiCuOS (presented in Figure 1). The unit cells extracted from this refinement are presented in Table 1, along with the DFT-computed ones that used the PBE0 functional. The average discrepancy between the experimental and DFT-computed structures is approximately $0.9 \%$, falling within the expected error range for the PBE0 functional. Going from $\mathrm{BiCuOS}$ to $\mathrm{BiAgOS}$, all the lattice parameters increase due to the larger ionic radius of $\mathrm{Ag}^{+}(114 \mathrm{pm})$ compared to $\mathrm{Cu}^{+}(74 \mathrm{pm}){ }^{49}$ The unit cell increase of BiAgOS compared to $\mathrm{BiCuOS}$ cannot be as large as the variation of radius between $\mathrm{Ag}^{+}$and $\mathrm{Cu}^{+}$for two reasons. First the Bi-O and $\mathrm{Bi}-\mathrm{S}$ bond lengths are kept unaffected as confirmed by their computed bond lengths (Table S2 in ESI) indicating that only the $\mathrm{Cu} / \mathrm{Ag}-\mathrm{S}$ bond increases by the substitution of $\mathrm{Cu}$ by $\mathrm{Ag}$. Second, the $\mathrm{Cu} / \mathrm{Ag}$ bond has a covalent character (see discussion on the electronic structure) and the covalent radii of $\mathrm{Cu}(132 \mathrm{pm})$ and $\mathrm{Ag}(145 \mathrm{pm})$ are relatively close. ${ }^{50}$

Table 1. Experimental and computed cell parameters of BiAgOS and $\mathrm{BiCuOS}$.

\begin{tabular}{llll}
\hline \hline Material & & $\mathrm{a}, \mathrm{b} / \AA$ & $\mathrm{c} / \AA$ \\
\hline \multirow{2}{*}{ BiAgOS } & Experiment & 3.913 & 9.228 \\
\cline { 2 - 4 } & DFT & 3.936 & 9.148 \\
\hline \multirow{2}{*}{ BiCuOS } & Experiment $^{21}$ & 3.868 & 8.561 \\
\cline { 2 - 4 } & DFT & 3.833 & 8.653 \\
\hline \hline
\end{tabular}

Then, the morphology was studied by applying the Scherrer formula to the (011) peak (located in the 24-25 $2 \theta$ range of the XRD pattern), which leads to coherence domains of 56 and $76 \mathrm{~nm}$ for BiCuOS and BiAgOS, respectively. The SEM images offer a better view of the crystallite sizes and shapes (Figure 3). For BiCuOS, the crystallites are truncated square pellets with edges ranging from approximately $100 \mathrm{~nm}$ to approximately $1 \mu \mathrm{m}$ and thicknesses of approximately $100 \mathrm{~nm}$. The geometry of the BiAgOS crystallites are less defined, but some truncated square pellets are observed with edges of approximately $10 \mu \mathrm{m}$ and thicknesses of approximately $1 \mu \mathrm{m}$; smaller particles are also present. 


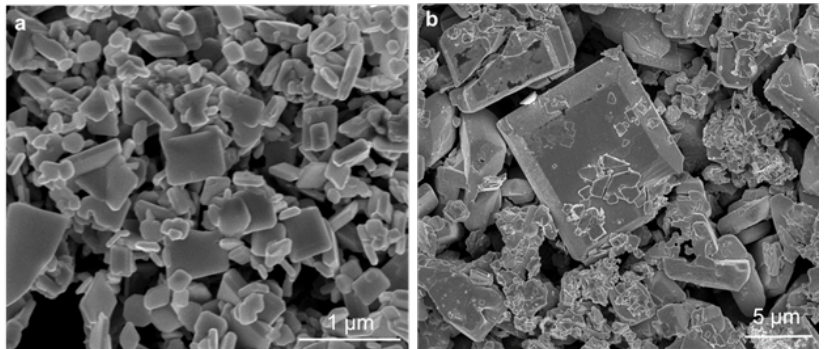

Figure 3. SEM images of (a) BiCuOS, (b) BiAgOS samples prepared by hydrothermal syntheses at $248{ }^{\circ} \mathrm{C}$ for $17 \mathrm{~h}$ and at $240{ }^{\circ} \mathrm{C}$ for $12 \mathrm{~h}$, respectively.

Figure 3 and Figure S2 show the HRTEM images, FFT patterns and EDX spectra of BiCuOS and BiAgOS. The BiCuOS particles have a well-defined crystallization, as indicated by the HRTEM images and the associated FFT patterns (Figure S2 a and b). The surface of the particle is covered by smaller particles (named P2 in Figure S2a) of poorly crystalized material rich in $\mathrm{O}$ and $\mathrm{Cu}$ that are ascribed to amorphous $\mathrm{CuO}_{\mathrm{x}}$. The HRTEM image of the BiAgOS particles (Figure $4 \mathrm{c}$ and d) and the related FFT processing agree with the crystal structure obtained from XRD. Amorphous particles of BiAgOS are also observed in the HRTEM image, possibly because of the reduction of $\mathrm{Ag}^{+}$to $\mathrm{Ag}^{0}$ induced by the electron beam, which inhibits the use of mapping analysis. The morphology of the particles obtained by hydrothermal synthesis is particularly sensitive to the synthesis temperature, as highlighted by the Figure S3. The specific areas evaluated by the BET method are 2.2 and $3.3 \mathrm{~m}^{2} \mathrm{~g}^{-1}$ for BiCuOS and BiAgOS, respectively.

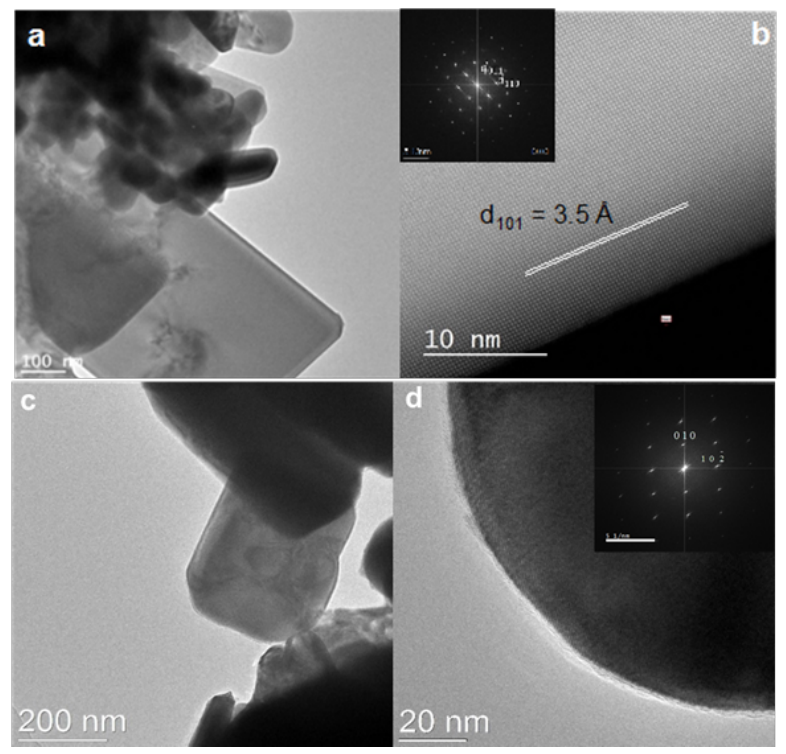

Figure 4. (a) TEM micrograph of BiCuOS and (b) its HR-TEM of the middle area (inset FFT pattern). (c) TEM micrograph of BiAgOS and (d) its HR-TEM (inset FFT pattern).
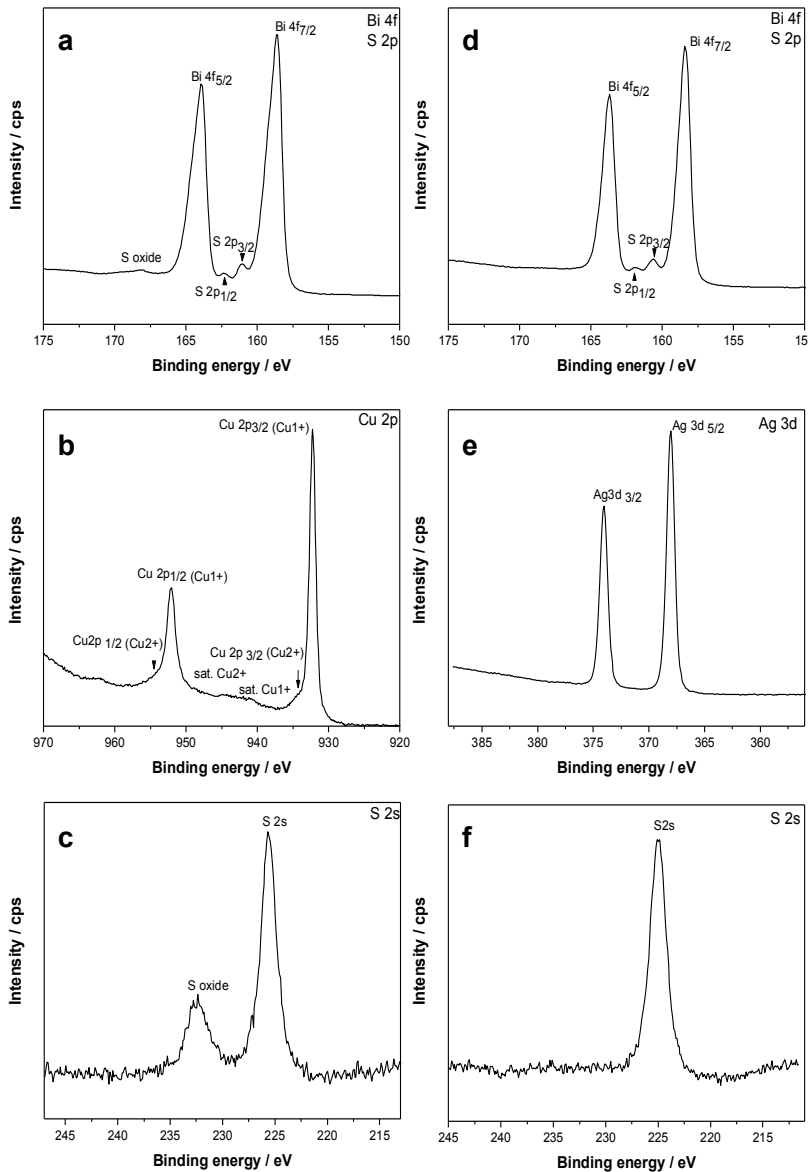

Figure 5. XPS spectra of BiCuOS $(a, b, c)$ and $\operatorname{BiAgOS}(d, e, f)$ for $\mathrm{Bi}(\mathrm{a}, \mathrm{d}), \mathrm{Cu}(\mathrm{b}), \mathrm{Ag}(\mathrm{e})$ and $\mathrm{S}(\mathrm{c}, \mathrm{f})$.

The ICP analysis we performed also indicates a ratio $\mathrm{Bi} / \mathrm{Cu}$ of $1 / 0.98$, which fit with an under-stoichiometry of copper in this material. $\mathrm{BiCuOS}$ is prone to creating $\mathrm{Cu}$ vacancies, giving a p-type character to this semiconductor. ${ }^{20,21}$ Previous literature reports agree on there being approximately $4 \% \mathrm{Cu}$ vacancies in this material, leading to the formula $\mathrm{BiCu}_{0.96} \mathrm{OS}$. In contrast, the $\mathrm{Bi} / \mathrm{Ag}$ ratio in $\mathrm{BiAgOS}$ is $1 / 1.02( \pm 0.02)$, meaning that the $\mathrm{Ag}$ does not create as many vacancies as $\mathrm{Cu}$.

The oxidation states of the surface atoms of $\mathrm{BiCuOS}$ and BiAgOS were investigated by XPS. The high-resolution spectra are presented in Figure 5, while wide scans are shown in the Supporting Information (Figure S4). Both materials exhibit a gap between the $\mathrm{Bi} 4 \mathrm{f}_{7 / 2}$ and $\mathrm{Bi} 4 \mathrm{f}_{5 / 2}$ peaks of $5.36 \mathrm{eV}$, confirming the $\mathrm{Bi}^{3+}$ oxidation state of this element. The XPS spectra of BiAgOS shows that there is only one oxidation state for $\mathrm{Ag}$ and $\mathrm{S}$ in the sample, whose XPS peaks correspond to $\mathrm{Ag}^{+}$and $\mathrm{S}^{2-}$. This analysis confirms the stoichiometric composition of BiAgOS and the absence of secondary phases on the surfaces of the particles. However, the $\mathrm{Cu} 2 \mathrm{p}_{1 / 2}$ and $2 \mathrm{p}_{3 / 2}$ peaks in $\mathrm{BiCuOS}$ confirm that this element is mainly at the +1 oxidation state, with a gap of $19.9 \mathrm{eV}$ between these two main peaks. $\mathrm{Cu}^{2+}$ species are also observed on this spectrum, characterized by shoulders on the $\mathrm{Cu}^{+}$peaks at $934.6 \mathrm{eV}$ and 954.9 $\mathrm{eV}$. This result supports the existence of the $\mathrm{CuO}_{\mathrm{x}}$ phase observed by HR-TEM, which the TEM imaging suggests is probably amorphous. The ionization peaks associated with $\mathrm{S}$ indicate that they are mostly sulfides, but traces of more oxidized $\mathrm{S}$ atoms are also observed for the $\mathrm{S}_{2 \mathrm{p} 3 / 2}$ and $\mathrm{S}_{2 \mathrm{~s}}$ binding energies, indicating sulfate species. This surface analysis 
confirms that $\mathrm{Cu}$ tends to leave the $\mathrm{BiCuOS}$ lattice, generating amorphous oxide phases on the surface, in marked contrast to $\mathrm{BiAgOS}$, which is less prone to surface oxidation.

\subsection{Electronic structure and $\mathrm{UV}-\mathrm{V}$ is characterization.}

The density of states (DOS) of BiCuOS and BiAgOS computed using the HSE06 functional are presented in Figure 5. The computed bandgaps, using HSE06 with spin-orbit coupling, are $1.22 \mathrm{eV}$ for $\mathrm{BiCuOS}$ and $1.44 \mathrm{eV}$ for BiAgOS. Since the bandgap of this semiconductor family is sensitive on the cell parameters (Figure S5), all electronic properties were computed on top of the experimental geometries instead of the optimized one with PBE0, while in very good agreement with the experiments.

For both compounds, the conduction band is almost entirely constituted by $\mathrm{Bi} 6 \mathrm{p}$ orbitals. It is important to recall that the low bandgap of $\mathrm{BiCuOX}$ materials is mainly due to the low energy level of these Bi $6 \mathrm{p}$ orbitals, mainly because of relativistic effects. ${ }^{51,52}$ In fact, a calculation without the spin-orbit coupling (SOC) for BiAgOS exhibits a $0.14 \mathrm{eV}$ shift of the conduction band, while the valence band position is almost unaffected. By drawing the conduction band orbital (Figure 7), it appears that this band corresponds to a non-bonding orbital built from the hybridization of $6 s$ and $6 p$ orbitals of Bismuth which is possible due to the lack of an inversion center at the $\mathrm{Bi}$ crystallographic position. ${ }^{53} \mathrm{~A}$ slight difference is observed between the valence band compositions of $\mathrm{BiCuOS}$ and $\mathrm{BiA}-$ gOS. The valence band of BiCuOS has a clear, approximately $1: 1$, combination of $\mathrm{Cu} 3 \mathrm{~d}$ and $\mathrm{S} 3 \mathrm{p}$ orbitals, highlighting the covalency of the $\mathrm{Cu}-\mathrm{S}$ bond. For BiAgOS, the valence band edge has a larger contribution from the $S 3 p$ orbitals and a smaller one from the Ag 4d orbitals. The hybrid level of the $\mathrm{S}$ $3 \mathrm{p}$ and $\mathrm{Ag} 4 \mathrm{~d}$ orbitals is located at a more positive potential than that of $\mathrm{S} 3 \mathrm{p}$ and $\mathrm{Cu} 3 \mathrm{~d}$, which corresponds to the higher oxidation potential of the $\mathrm{Ag}^{2+} / \mathrm{Ag}^{+}$redox couple compared to the $\mathrm{Cu}^{2+} / \mathrm{Cu}^{+}$redox couple. This is further confirmed by the representation of the orbitals involved in the valence band edges (Figure 7) where a strong combination of $\mathrm{S}$ and $\mathrm{Cu}$ orbitals clearly appears in contrast with the small combination of S and Ag orbitals. The weaker covalence of the Ag-S bond compared to the $\mathrm{Cu}-\mathrm{S}$ bond is also supported by an atomic charge calculation, giving a higher ionicity of $\mathrm{Ag}\left(q_{\mathrm{Ag}}=\right.$ $+0.57)$ than $\mathrm{Cu}\left(q_{\mathrm{Cu}}=+0.49\right)$. The band structure of BiAgOS is very similar to that of $\mathrm{BiCuOS}$ and is characterized by an indirect bandgap with a minimum of the conduction band at the Z-point and a maximum of the valence band at a $\mathrm{k}$ vector between the $\Gamma$ - and M-points (Figure 8).
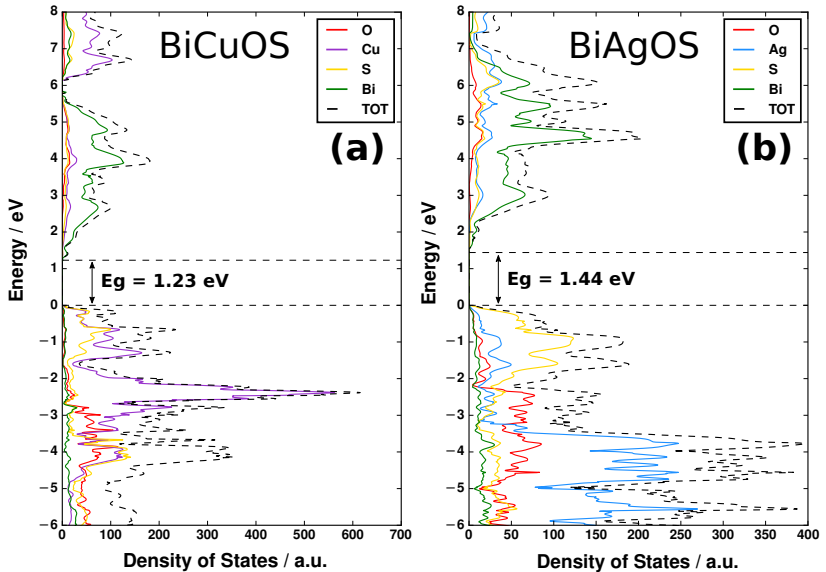

Figure 6. Density of states of (a) BiCuOS and (b) BiAgOS. The green, yellow, blue and red colors correspond to the projection of the $\mathrm{Bi}, \mathrm{S}, \mathrm{Cu}$ and $\mathrm{O}$ atoms, respectively. The black dashed line is the total DOS.

From the DFT calculation, the electronic structure demonstrates an indirect transition for excitation at the bandgap. The experimental data from the reflectance absorption spectrum of the powders confirm these computed bandgaps. The KubelkaMunk function spectra are presented in Figure 9a, and the Tauc representations (used to extract bandgaps) are plotted for the indirect bandgaps in Figure S6. Experimentally, the bandgaps are $\sim 1.1 \mathrm{eV}$ and $\sim 1.5 \mathrm{eV}$ for BiCuOS and BiAgOS, respectively. The increase in the measured bandgap agrees with those estimated by the DFT calculations. The absorption coefficients are also computed, and the results are presented in Figure $9 \mathrm{~b}$. In the $500-800 \mathrm{~nm}$ range, the absorption coefficient of $\mathrm{BiAgOS}$ remains modest, with values of approximately $2 \times$ $10^{4} \mathrm{~cm}^{-1}$. However, the absorption coefficient increases quickly below $500 \mathrm{~nm}$ to reach values higher than $10^{5} \mathrm{~cm}^{-1}$. In this range of wavelengths, the absorption coefficient of $\mathrm{BiCuOS}$ is always larger than that of BiAgOS.

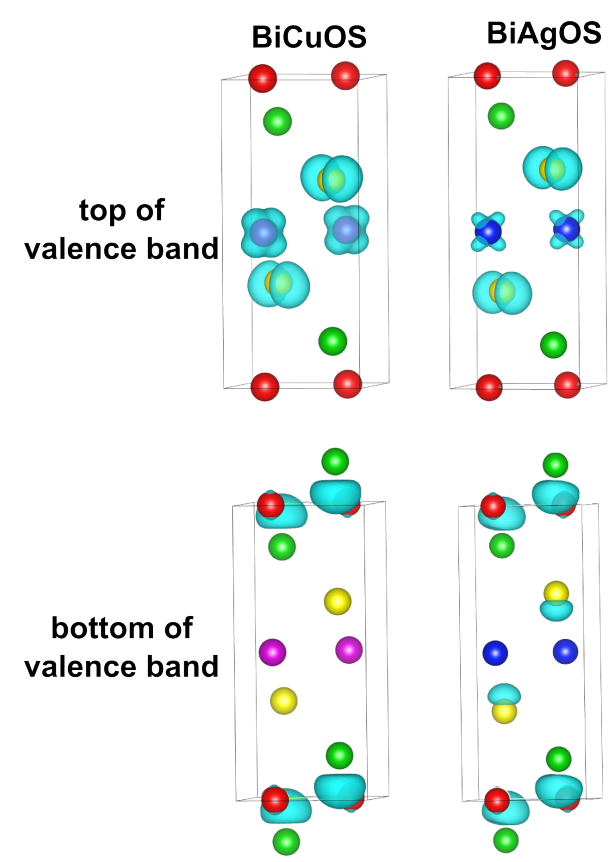

Figure 7. Modulus of the crystalline orbital corresponding for the top of valence band and bottom of conduction band (isovalue $4 \times$ 
$10^{-5}$ a.u.). Red, green, blue, purple and yellow colors correspond to $\mathrm{O}, \mathrm{Bi}, \mathrm{Ag}, \mathrm{Cu}$ and $\mathrm{S}$ atoms respectively.
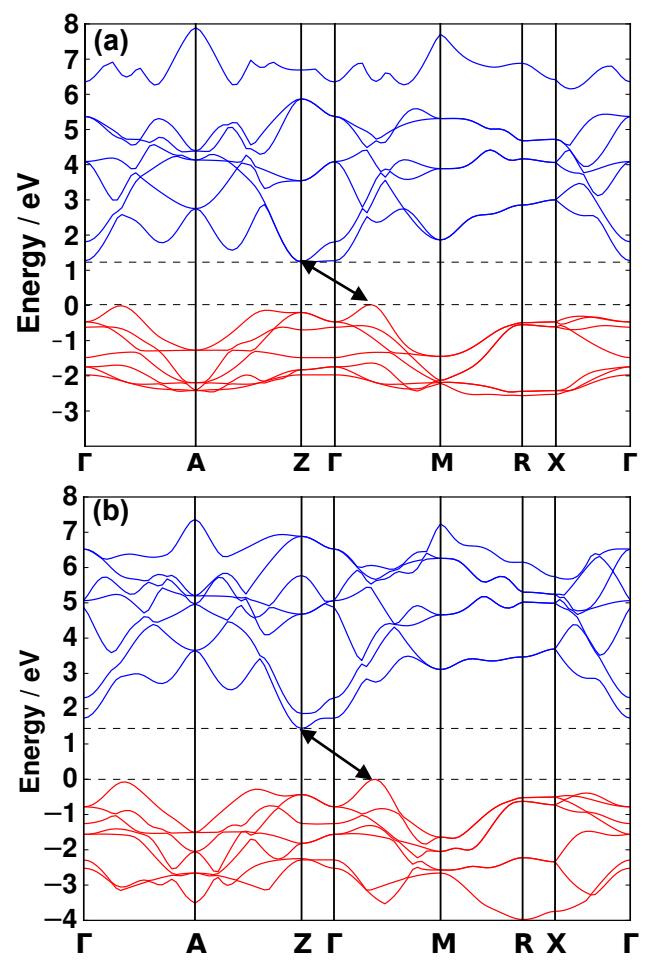

Figure 8. Band structures of (a) BiCuOS and (b) BiAgOS. The red and blue lines are the occupied and empty bands, respectively. The black arrows indicate the indirect bandgaps.
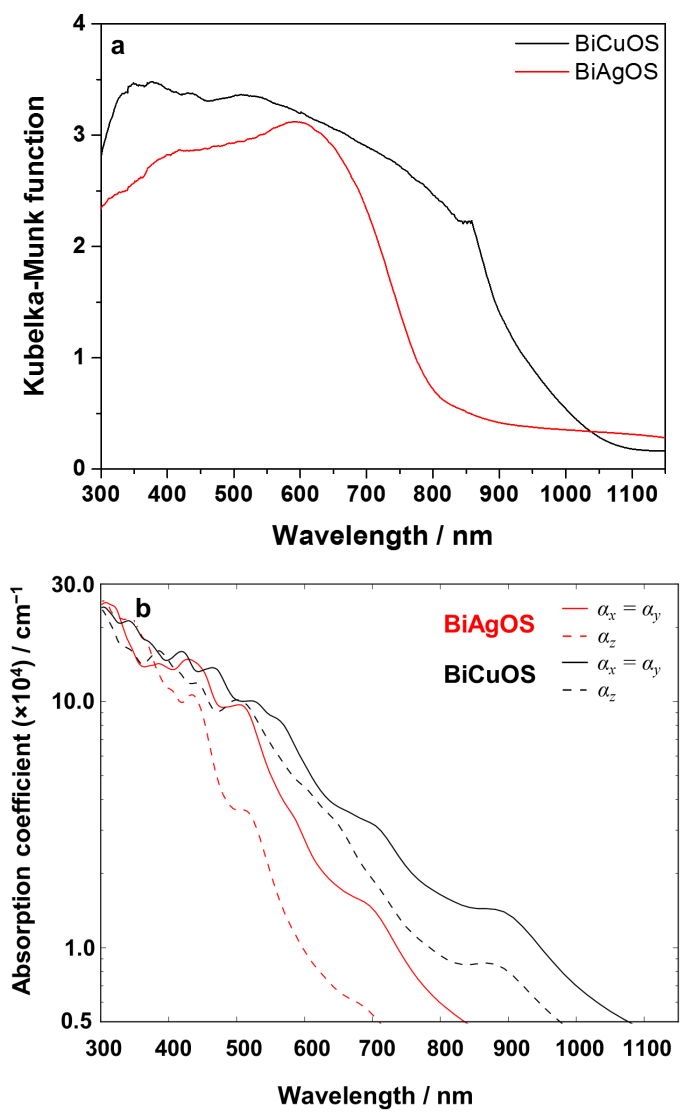

Figure 9. (a) Kubelka-Munk absorption spectra of BiCuOS (black) and BiAgOS (red), (b) computed absorption spectra of BiCuOS (black) and BiAgOS (red).

\subsection{Band positions.}

For photocatalytic reactions, the band positions of the semiconductor materials play a role as important as the bandgap itself because these energies generally represent the oxidation potential of holes (for the valence band position) and the reduction potential of electrons (for the conduction band). Two experimental setups were used to determine the band positions, based on Mott-Schottky plots of the semiconductor electrodes and on PESA of the powder pellets.

To obtain the Mott-Schottky plots of the intrinsic semiconductor materials, a dense pellet of the material that minimizes the grain boundary was needed. To determine the optimum sintering conditions, we performed a TGA analysis both in air and in $\mathrm{N}_{2}$ atmospheres for both oxysulfides. The TGA analyses are shown in the Supporting Information in Figure S6. $\mathrm{BiCuOS}$ starts to decompose (oxidize) at $300{ }^{\circ} \mathrm{C}$ in air while $\mathrm{BiAgOS}$ remains stable until $400{ }^{\circ} \mathrm{C}$ in air. After a gain in mass for both compounds due to oxidation, a mass loss is measured above $650{ }^{\circ} \mathrm{C}$ that corresponds to the evaporation of sulfur (see Supporting Information Figure S7-S9). Under nitrogen, both compounds remain stable up to $\sim 550{ }^{\circ} \mathrm{C}$, and a mass loss is recorded beyond this temperature, corresponding to the evaporation of sulfur (see Supporting Information Figure S7-S9). After consideration of these data, the BiCuOS and BiAgOS pellets were sintered in a $\mathrm{N}_{2}$ atmosphere at $400{ }^{\circ} \mathrm{C}$ for $6 \mathrm{~h}$. The Mott-Schottky curves are presented in Figure 10. We used equation (3) to extract the flat band potentials and equation (4) to obtain the valence band position:

$$
\begin{aligned}
& \frac{1}{C_{S C}^{2}}=\frac{2}{e \varepsilon_{0} \varepsilon_{r} A^{2} N_{A}}\left(-E+E_{f b}-\frac{k_{B} T}{e}\right) \\
& E_{V B}-E_{f b}=k T \ln \left(\frac{N_{A}}{N_{V}}\right)
\end{aligned}
$$

where $C_{\mathrm{SC}}$ is the material capacitance, $e$ is the elementary charge, $\varepsilon_{0}$ and $\varepsilon_{\mathrm{r}}$ are the vacuum and material permittivities, respectively, A is the specific surface of the pellet, $N_{\mathrm{A}}$ is the acceptor concentration, $E$ is the potential applied to the material, $E_{\mathrm{fb}}$ is the flat band potential, $k_{\mathrm{B}}$ is the Boltzmann constant, $T$ is the temperature, $E_{\mathrm{VB}}$ is the valence band energy, and $N_{\mathrm{V}}$ is the effective valence band density of states. The equation used to compute $N_{\mathrm{V}}$ for $\mathrm{BiCuOS}$ and $\mathrm{BiAgOS}$ is presented in the Supporting Information and is based on the hole effective mass extracted from the DFT-calculated band structure.

First, the negative slopes measured for both compounds are consistent with a p-type character. While this electronic property is frequently reported for $\mathrm{Cu}(+1)$ based materials, because of the low formation energy of $\mathrm{Cu}(+1)$ vacancies, it is much less observed for $\operatorname{Ag}(+1)$ based semiconductors. The large resistivity of the BiAgOS samples prevented us from performing Hall effect measurement, which is the common experimental setup used to characterize majority charge carriers in a semiconductor. This p-type character of BiAgOS could come from $\mathrm{Ag}$ vacancies as already observed in $\mathrm{Sr}_{2} \mathrm{AO}_{2} \mathrm{M}_{2} \mathrm{Se}_{2}$ $(\mathrm{A}=\mathrm{Co}, \mathrm{Mn} ; \mathrm{M}=\mathrm{Cu}, \mathrm{Ag}){ }^{54} \mathrm{~A}_{2}^{\mathrm{I}}-\mathrm{Zn}-\mathrm{A}^{\mathrm{IV}}-\mathrm{S}_{4}\left(\mathrm{~A}^{\mathrm{I}}=\mathrm{Cu}\right.$ and $\mathrm{Ag}$; $\mathrm{A}^{\mathrm{IV}}=\mathrm{Sn}$ and $\left.\mathrm{Ge}\right),{ }^{55}$ and $\mathrm{La}_{5} \mathrm{Ti}_{2} \mathrm{MS}_{5} \mathrm{O}_{7}(\mathrm{M}=\mathrm{Ag}, \mathrm{Cu}) .{ }^{56}$ The large resistivity of the material suggests that the vacancy concentration remains too low to be quantified by conventional elemental analysis including ICP. 
The exact surface area of the material exposed to the electrolyte is unknown, preventing the extraction of a reliable donor concentration, $N_{\mathrm{A}}$. Fitting the Mott-Schottky curve with equation (3) leads to flat band potentials of $0.55 \mathrm{~V}$ and $0.94 \mathrm{~V}$ vs. RHE for $\mathrm{BiCuOS}$ and $\mathrm{BiAgOS}$, respectively. After correction with equation (4), the valence band energies are determined, compared to vacuum, at $-4.88 \mathrm{eV}$ and $-5.34 \mathrm{eV}$ for $\mathrm{BiCuOS}$ and BiAgOS, respectively. The measured flatband potentials of $\mathrm{BiCuOS}$ and $\mathrm{BiAgOS}$ were $\mathrm{pH}$ independent in the 6-10 range of $\mathrm{pH}$ (see Figure $\mathrm{S} 10$ in SI).

To support these valence band positions, we also measured this property with PESA. Figure 11 presents the cube root of the counting rate as a function of the photon energy. The crossing point of the linear part of the curve with the $\mathrm{x}$-axis should correspond to the valence band energies. Valence band positions of $-4.97 \mathrm{eV}$ and $-5.30 \mathrm{eV}$ vs. vacuum are measured for $\mathrm{BiCuOS}$ and $\mathrm{BiAgOS}$, respectively. These values are very close to the ones determined by electrochemistry using the Mott-Schottky approach. Figure 12 shows the global electronic structure of the $\mathrm{BiCuOS}$ and $\mathrm{BiAgOS}$ semiconductors.
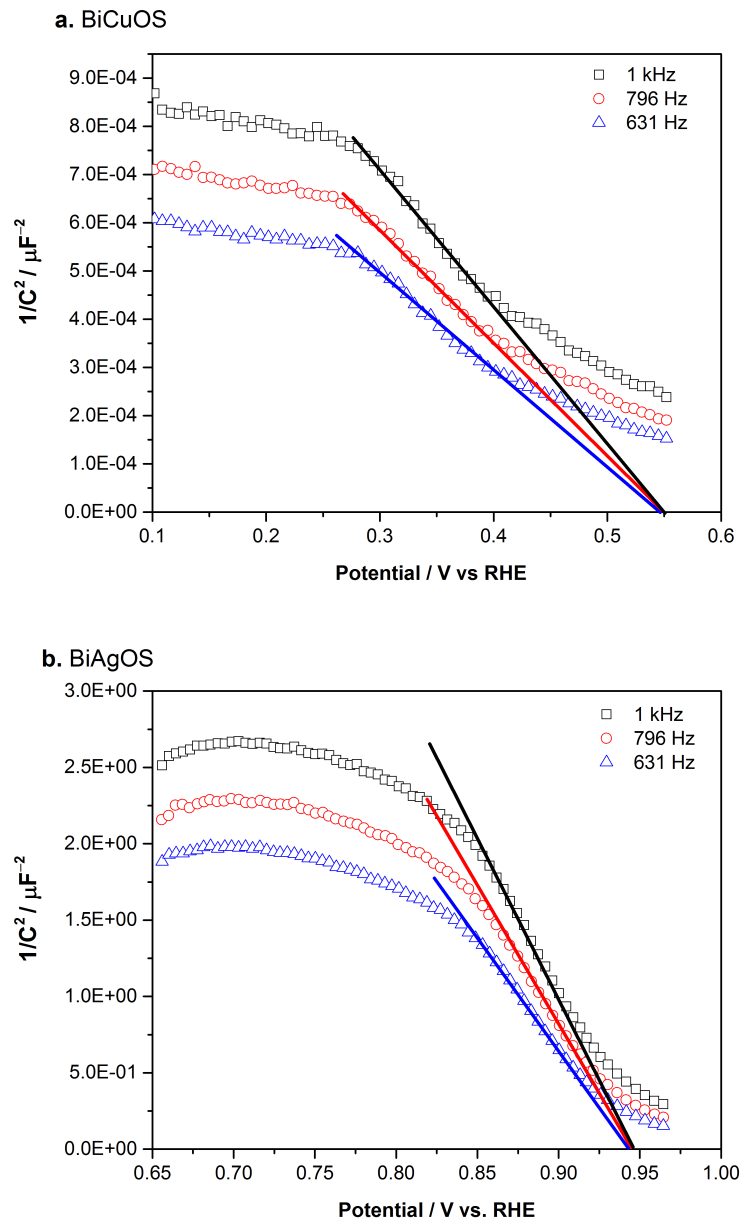

Figure 10. Mott-Schottky plots for pellets of (a) BiCuOS and (b) BiAgOS in $0.2 \mathrm{M} \mathrm{Na}_{2} \mathrm{SO}_{4}$ at $\mathrm{pH} 6$.

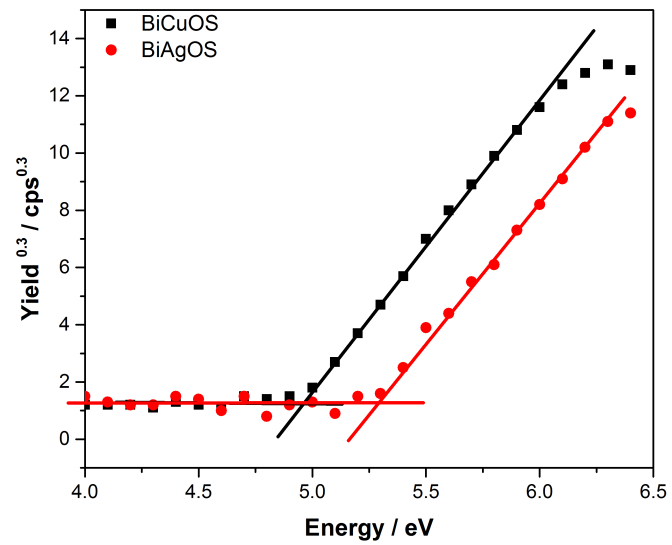

Figure 11. Photoelectron spectroscopy measurements of BiCuOS/ ITO and BiAgOS/ ITO electrodes.

Our preliminary attempt to explore these materials for photoconversion is shown in Figure S11, where photocatalytic $\mathrm{H}_{2}$ evolution reaction is reported. $\mathrm{Ru}$ catalyst was photodeposited during the photocatalytic measurement in the presence of 0.05 $\mathrm{M} \mathrm{Na} 2 \mathrm{~S}$ and $0.3 \mathrm{M} \mathrm{Na}_{2} \mathrm{SO}_{3}$. Although several attempts were tried using $\mathrm{BiCuOS}$, this semiconductor did not evolve any detectable amount of $\mathrm{H}_{2}$. On the contrary, BiAgOS successfully generated $\mathrm{H}_{2}$. The photocatalytic rate is relatively small, but it is remarkable that $\mathrm{H}_{2}$ was evolved using a material with 1.5 $\mathrm{eV}$ bandgap (i.e. $850 \mathrm{~nm}$ ). This finding confirms that the conduction band of this material is reductive enough to evolve $\mathrm{H}_{2}$. While adapted for $\mathrm{H}_{2}$ production, the valence band potential of BiAgOS remains too positive to consider this material for water oxidation. The material has potential for photocatalytic application such as in tandem cell or Z-scheme cell for water splitting. A monotonic increase in the amount of evolved $\mathrm{H}_{2}$ was observed for $8 \mathrm{~h}$, but noticeable deactivation was inevitable. The deactivation may originate from $\mathrm{Ag}^{+}$reduction to metallic state, as can be evident from the metallic Ag characteristics in the PESA measurement of the material after the photocatalysis (Figure S12). Further studies are necessary to apply a protection strategy to avoid photoreduction of BiAgOS itself. 


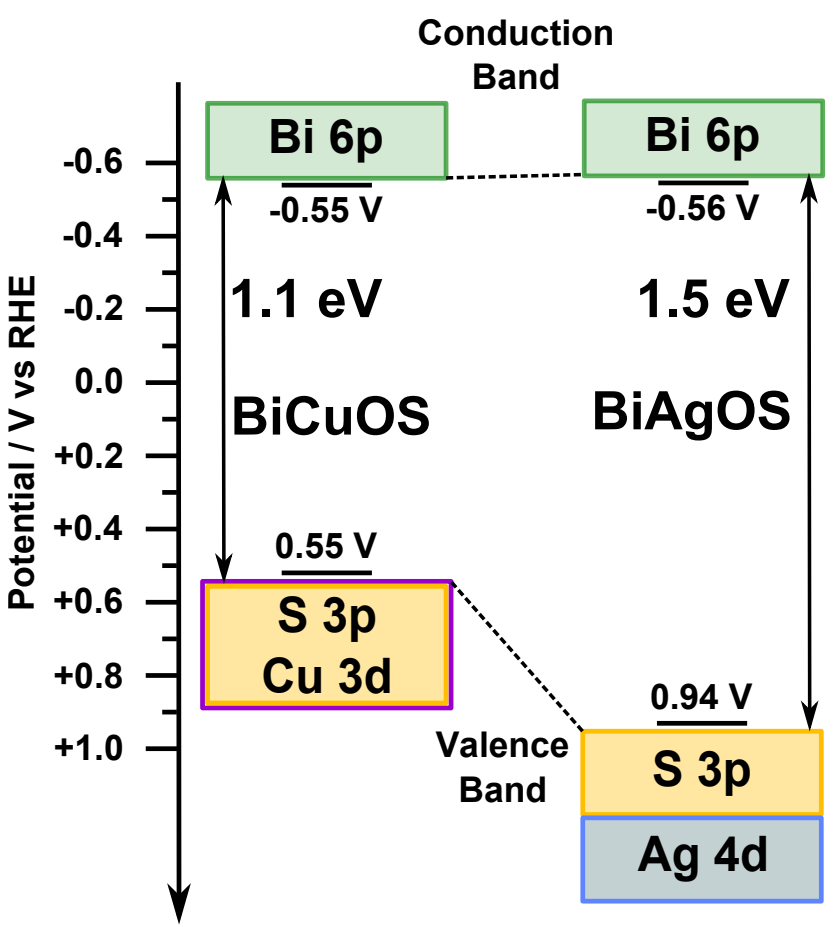

Figure 12. Schematic showing the band positions for $\mathrm{BiCuOS}$ and $\mathrm{BiAgOS}$ with respect to RHE.

\subsection{Dielectric and conducting properties.}

To complete the photoelectrochemical characterization of these minerals, we computed their dielectric constants, effective masses and exciton binding energies. In a dielectric material, two main factors contribute to the static dielectric constant: the contribution from the electron density $\left(\varepsilon_{\infty}\right)$ and the contribution from the ion vibrations $\left(\varepsilon_{\mathrm{vib}}\right)$.

$$
\varepsilon_{r}=\varepsilon_{\infty}+\varepsilon_{v i b}
$$

The computed $\varepsilon_{\infty}$ and $\varepsilon_{\mathrm{r}}$ of $\mathrm{BiCuOS}$ and BiAgOS are presented in Table 2 along with all the other measured or computed properties. The infinite dielectric constant is very similar for both compounds because this property is dominated by the polarizable electron density of the $\mathrm{Bi}$ atom present in the two semiconductors. The vibrational contribution is notably large for both systems especially for BiAgOS. The interlayer vibrational contribution $(<001>$ direction) is almost the same for the two compounds, but the intralayer $(<110>$ direction) is doubled for $\mathrm{BiAgOS}$ than for $\mathrm{BiCuOS}$. The reason for this large increase can be associated with the fact that silver is heavier than copper, giving softer modes, and the higher ionicity of BiAgOS, as discussed for the electronic structure description.
Table 2. Summary of the measured and computed properties for BiCuOS and BiAgOS. For VB and CB positions are obtained from Mott-Schottky (MS) and PESA (P) measurements respectively. The symbols $\perp$ and $\|$ correspond to the $<001>$ and $<110>$ crystallographic directions respectively.

\begin{tabular}{|c|c|c|c|c|}
\hline \multirow[b]{3}{*}{$\boldsymbol{E}_{\mathrm{g}} / \mathrm{eV}$} & \multicolumn{2}{|l|}{$\mathrm{BiCuOS}$} & \multicolumn{2}{|l|}{ BiAgOS } \\
\hline & Exp & DFT & Exp & DFT \\
\hline & 1.15 & 1.22 & 1.50 & 1.42 \\
\hline \multirow{2}{*}{$\varepsilon_{\infty}$} & \multirow{2}{*}{--} & $10.0 \|$ & \multirow{2}{*}{--} & $9.8 \|$ \\
\hline & & $7.5 \perp$ & & $8.7 \perp$ \\
\hline \multirow{2}{*}{$\varepsilon_{\mathrm{r}}$} & \multirow{2}{*}{--} & $56.7 \|$ & \multirow{2}{*}{--} & 119.7 || \\
\hline & & $23.5 \perp$ & & $23.7 \perp$ \\
\hline \multirow{2}{*}{$\boldsymbol{m}_{\mathrm{e}}{ }^{* /} m_{\mathrm{e}}$} & \multirow{2}{*}{--} & $0.42 \|$ & \multirow{2}{*}{--} & $0.23 \|$ \\
\hline & & $0.68 \perp$ & & $0.30 \perp$ \\
\hline \multirow{2}{*}{$\boldsymbol{m}_{\mathbf{h}} * / m_{\mathrm{e}}$} & \multirow{2}{*}{--} & $0.33 \|$ & \multirow{2}{*}{--} & $0.45 \|$ \\
\hline & & $1.36 \perp$ & & $0.78 \perp$ \\
\hline $\boldsymbol{E}_{\mathbf{b}} / \mathrm{meV}$ & -- & 2.0 & -- & 0.4 \\
\hline \multirow{2}{*}{$\begin{array}{l}\text { VB / eV } \\
\text { vs vac. }\end{array}$} & -4.97 (MS) & \multirow{2}{*}{--} & \multirow{2}{*}{$\begin{array}{l}-5.30(\mathrm{MS}) \\
-5.34(\mathrm{P})\end{array}$} & \\
\hline & $-4.88(\mathrm{P})$ & & & -- \\
\hline \multirow{2}{*}{$\begin{array}{l}\text { CB } / \mathrm{eV} \\
\text { vs vac. }\end{array}$} & $-3.82(\mathrm{MS})$ & \multirow{2}{*}{--} & \multirow{2}{*}{$\begin{array}{l}-3.80(\mathrm{MS}) \\
-3.84(\mathrm{P})\end{array}$} & --- \\
\hline & $-3.73(\mathrm{P})$ & & & -- \\
\hline
\end{tabular}

Effective masses are related to the charge carrier mobilities through equation (6), where $\mu$ is the charge carrier mobility, $e$ is the elementary charge, and $\tau$ is the collision time. Lower effective masses give better charge delocalization and charge mobility.

$$
\mu=\frac{e \tau}{m^{*}}
$$

For $\mathrm{BiCuOS}$, the conduction band is degenerate at the $\mathrm{Z}$ point leading to light and heavy electrons. The electron conductivity is mainly governed by light electrons, for that reason only the effective mass of light electrons is reported.

In these layered materials, the electron and hole effective masses are smaller in the intralayer direction than in the interlayer one, in agreement with the view of a hole localized in a $\mathrm{Cu}-\mathrm{S}$ layer and an electron in the $\mathrm{Bi}$ layer. Replacing $\mathrm{Cu}$ with $\mathrm{Ag}$ notably reduces the effective masses of both holes and electrons, except for holes in the $<110>$ direction, which may have arisen from the weaker covalency of the Ag-S bond compared to the $\mathrm{Cu}-\mathrm{S}$ bond. The obtained effective masses fit with the good charge carrier mobilities for these two semiconductors.

Another computed property is the exciton binding energy, which corresponds to the energy necessary to dissociate the electron-hole pair generated by light absorption into free charge carriers. If this energy is lower than the thermal room temperature energy $\left(k_{\mathrm{B}} T \sim 25 \mathrm{meV}\right)$, exciton dissociation will be efficient inside the material. For semiconductors with large dielectric constants, such as those investigated here, the MottWannier model of the exciton is particularly efficient for eval- 
uating the binding energy because it treats the exciton as a hydrogen atom in a dielectric medium. The computed values are extremely low (see Table 2) for both compounds because of the very large dielectric constants of these materials. Consequently, efficient exciton dissociation is expected both for $\mathrm{BiCuOS}$ and $\mathrm{BiAgOS}$.

In summary, this investigation of $\mathrm{BiCuOS}$ and $\mathrm{BiAgOS}$ confirms that the optoelectronic properties of this family of structures can be tuned by ion substitution (e.g., $\mathrm{Cu}$ vs. Ag). We prove that the substitution of $\mathrm{Cu}$ by an isovalent element is possible and leads to noticeable changes in electronic properties. The tuning of BiAgOS electronic structure to adapt band positions for specific photocatalytic applications can also be possible by doping other crystallographic positions such as substituting $\mathrm{Bi}$ with $\mathrm{La}$ to shift the bandgap to the $1.8-2.2 \mathrm{eV}$ range ideal for water splitting. Thus, because of its stability and its larger bandgap, the BiAgOS appears to be a more interesting starting material compared to $\mathrm{BiCuOS}$ for designing representatives of the $\mathrm{BiCuOX}$ family for photoconversion applications.

\section{CONCLUSIONS}

We demonstrated the syntheses of a single-phase BiAgOS layered structure and an isostructural $\mathrm{BiCuOS}$ species, which were achieved by a hydrothermal protocol. BiAgOS is less prone to $\mathrm{Ag}$ under-stoichiometry compared to $\mathrm{Cu}$ in $\mathrm{BiCuOS}$, while keeping a p-type character. DFT calculations using the HSE06 functional demonstrate that the electronic structures of $\mathrm{BiCuOS}$ and BiAgOS have indirect transitions of photon absorption with bandgaps of 1.2 and $1.5 \mathrm{eV}$, respectively. The valence band has a large contribution from $\mathrm{S}$ orbitals in BiA$\mathrm{gOS}$, in contrast to $\mathrm{BiCuOS}$ where the $\mathrm{Cu}$ and $\mathrm{S}$ orbitals equally contribute. BiAgOS is more ionic in nature than $\mathrm{BiCuOS}$, resulting in a very large dielectric constant and making it very interesting for photoconversion applications because the material could efficiently screen photogenerated charges. With their very low effective masses, even in the interlayer direction, good charge mobilities are expected. Due to their relatively low bandgap and their p-type characters, BiCuOS and BiAgOS can be considered as interesting starting compositions to develop new semiconductors for photovoltaic or Zscheme photocatalytic applications.

\section{Corresponding Author}

* Authors for correspondence: Tangui Le Bahers, tangui.le_bahers@ens-lyon.fr; Kazuhiro Takanabe, kazuhiro.takanabe@kaust.edu.sa

\section{Acknowledgement}

$\mathrm{AC}$ and TLB acknowledge the PSMN computation center for providing calculation resources.

\section{SUPPORTING INFORMATION}

Table S1. Results of the Rietveld refinement. Figure S1. X-ray diffraction pattern and Rietveld refinement of BiAgOS; Figure S2. HRTEM and EDX analysis of BiCuOS. Table S2: Structural parameters from the PBE0 optimized geometries. Figure S3. SEM images of $\mathrm{BiCuOS}$ particles obtained from $180^{\circ} \mathrm{C}$ and $200^{\circ} \mathrm{C}$ of synthesis temperature. Figure S4. Large XPS spectra of $\mathrm{BiCuOS}$ and BiAgOS. Figure S5. Variation of the BiAgOS bandgap as a function of the cell parameters. Figure S6. Tauc plot of $\mathrm{BiCuOS}$ and $\mathrm{BiAgOS}$ used to determine the bandgaps. Figure S7-S9. Thermogravimetric analysis and corresponding XRD patterns of BiCuOS and BiAgOS. Figure S10. Mott-Schottky curves of BiCuOS obtained at $\mathrm{pH} 6$ and $\mathrm{pH} 10$ drawn versus RHE reference electrodes. Figure S11. $\mathrm{H}_{2}$ evolution rate obtained from $\mathrm{BiCuOS}$ and $\mathrm{BiAgOS}$ powder system. Figure S12. Photoelectron yield spectroscopy measurements of $\mathrm{BiAgOS} / \mathrm{ITO}$ electrodes in air after photocatalytic reaction. This material is available free of charge via the Internet at http://pubs.acs.org.

\section{REFERENCES}

1. Johnston, B.; Mayo, M. C.; Khare, A., Hydrogen: the energy source for the $21^{\text {st }}$ century. Technovation 2005, 25, 569-585.

2. Hoffmann, P., Tomorrow's Energy. MIT Press: 2004; Vol. 1.

3. Sivula, K.; van de Krol, R., Semiconducting materials for photoelectrochemical energy conversion. Nat. Rev. Mater. 2016, 1, 15010 .

4. Hisatomi, T.; Kubota, J.; Domen, K., Recent advances in semiconductors for photocatalytic and photoelectrochemical water splitting. Chem. Soc. Rev. 2014, 43, 7520-7535.

5. Walter, M. G.; Warren, E. L.; McKone, J. R.; Boettcher, S. W.; Mi, Q.; Santori, E. A.; Lewis, N. S., Solar water splitting cells. Chem. Rev. 2010, 110, 6446-73.

6. Li, X.; Yu, J. G.; Low, J. X.; Fang, Y. P.; Xiao, J.; Chen, $\mathrm{X}$. B., Engineering heterogeneous semiconductors for solar water splitting. J. Mater. Chem. A 2015, 3, 2485-2534.

7. Takanabe, K.; Domen, K., Toward Visible Light Response: Overall Water Splitting Using Heterogeneous Photocatalysts. Green, 2011, 1, 313-322.

8. Nocera, D. G., The Artificial Leaf. Acc. Chem. Res. 2012, $45,767-776$

9. Minegishi, T.; Nishimura, N.; Kubota, J.; Domen, K., Photoelectrochemical properties of $\mathrm{LaTiO}_{2} \mathrm{~N}$ electrodes prepared by particle transfer for sunlight-driven water splitting. Chem. Sci. 2013, 4, 1120-1124.

10. Higashi, M.; Abe, R.; Takata, T.; Domen, K., Photocatalytic Overall Water Splitting under Visible Light Using $\mathrm{ATaO}_{2} \mathrm{~N}(\mathrm{~A}=$ $\mathrm{Ca}, \mathrm{Sr}, \mathrm{Ba})$ and $\mathrm{WO}_{3}$ in a $\mathrm{IO}_{3}{ }^{-} / \mathrm{I}^{-}$Shuttle Redox Mediated System. Chem. Mater. 2009, 21, 1543-1549.

11. Liu, J. Y.; Hisatomi, T.; Katayama, M.; Minegishi, T.; Kubota, J.; Domen, K., Effect of particle size of $\mathrm{La}_{5} \mathrm{Ti}_{2} \mathrm{CuS}_{5} \mathrm{O}_{7}$ on photoelectrochemical properties in solar hydrogen evolution. J. Mater. Chem. A 2016, 4, 4848-4854.

12. Wang, Y.; Wang, X. C.; Antonietti, M., Polymeric Graphitic Carbon Nitride as a Heterogeneous Organocatalyst: From Photochemistry to Multipurpose Catalysis to Sustainable Chemistry. Angew. Chem. Int. Ed. 2012, 51, 68-89.

13. Ong, W. J.; Tan, L. L.; Ng, Y. H.; Yong, S. T.; Chai, S. P., Graphitic Carbon Nitride $\left(\mathrm{g}-\mathrm{C}_{3} \mathrm{~N}_{4}\right)$-Based Photocatalysts for Artificial Photosynthesis and Environmental Remediation: Are We a Step Closer To Achieving Sustainability? Chem. Rev. 2016, 116, 71597329 .

14. Bhunia, M. K.; Melissen, S.; Parida, M. R.; Sarawade, P.; Basset, J. M.; Anjum, D. H.; Mohammed, O. F.; Sautet, P.; Le Bahers, T.; Takanabe, K., Dendritic Tip-on Polytriazine-Based Carbon Nitride Photocatalyst with High Hydrogen Evolution Activity. Chem. Mater. 2015, 27, 8237-8247.

15. Prevot, M. S.; Sivula, K., Photoelectrochemical Tandem Cells for Solar Water Splitting. J. Phys. Chem. C 2013, 117, 1787917893.

16. Pinaud, B. A.; Benck, J. D.; Seitz, L. C.; Forman, A. J.; Chen, Z. B.; Deutsch, T. G.; James, B. D.; Baum, K. N.; Baum, G. N.; Ardo, S.; Wang, H. L.; Miller, E.; Jaramillo, T. F., Technical and economic feasibility of centralized facilities for solar hydrogen pro- 
duction via photocatalysis and photoelectrochemistry. Energy Environ. Sci. 2013, 6, 1983-2002.

17. Hiramatsu, H.; Yanagi, H.; Kamiya, T.; Ueda, K.; Hirano, M.; Hosono, H., Crystal structures, optoelectronic properties, and electronic structures of layered oxychalcogenides MCuOCh $(\mathrm{M}=\mathrm{Bi}$, $\mathrm{La} ; \mathrm{Ch}=\mathrm{S}, \mathrm{Se}, \mathrm{Te})$ : Effects of electronic configurations of $\mathrm{M}^{3+}$ ions. Chem. Mater. 2008, 20, 326-334.

18. Khan, W.; Azam, S.; Kanoun, M. B.; Goumri-Said, S., Optoelectronic structure and related transport properties of $\mathrm{BiCuSeO}-$ based oxychalcogenides: First principle calculations. Solid State Sci. 2016, 58, 86-93.

19. Richard, A. P.; Russell, J. A.; Zakutayev, A.; Zakharov, L. N.; Keszler, D. A.; Tate, J., Synthesis, structure, and optical properties of $\mathrm{BiCuOCh}(\mathrm{Ch}=\mathrm{S}, \mathrm{Se}$, and Te). J. Solid State Chem. 2012, 187, 1519.

20. Berthebaud, D.; Guilmeau, E.; Lebedev, O. I.; Maignan, A.; Gamon, J.; Barboux, P., The $\mathrm{BiCu}_{1-\mathrm{x}}$ OS oxysulfide: Copper deficiency and electronic properties. J. Solid State Chem. 2016, 237, 292299.

21. Sheets, W. C.; Stampler, E. S.; Kabbour, H.; Bertoni, M. I.; Cario, L.; Mason, T. O.; Marks, T. J.; Poeppelmeier, K. R., Facile synthesis of BiCuOS by hydrothermal methods. Inorg. Chem. 2007, 46, 10741-10748.

22. Stampler, E. S.; Sheets, W. C.; Bertoni, M. I.; Prellier, W.; Mason, T. O.; Poeppelmeier, K. R., Temperature Driven Reactant Solubilization Synthesis of BiCuOSe. Inorg. Chem. 2008, 47, 1000910016.

23. Le Bahers, T.; Rerat, M.; Sautet, P., Semiconductors Used in Photovoltaic and Photocatalytic Devices: Assessing Fundamental Properties from DFT. J. Phys. Chem. C 2014, 118, 5997-6008.

24. Wang, H. C.; Li, S.; Liu, Y. C.; Ding, J. X.; Lin, Y. H.; Xu, H. M.; Xu, B.; Nan, C. W., Bi $1_{1-x} \mathrm{La}_{x} \mathrm{CuSeO}$ as New Tunable Full Solar Light Active Photocatalysts. Sci. Rep. 2016, 6, 24620.

25. White, R. T.; Kumar, B.; Kumari, S.; Spurgeon, J. M., Simulations of non-monolithic tandem solar cell configurations for electrolytic fuel generation. J. Mater. Chem. A 2017, 5, 13112-13121.

26. Lardhi, S.; Curutchet, A.; Cavallo, L.; Harb, M.; Le Bahers, $\mathrm{T}$., $\mathrm{Ab}$ initio assessment of $\mathrm{Bi}_{1-\mathrm{x}} \mathrm{RE}_{\mathrm{x}} \mathrm{CuOS}(\mathrm{RE}=\mathrm{La}, \mathrm{Gd}, \mathrm{Y}, \mathrm{Lu})$ solid solutions as a semiconductor for photochemical water splitting. Phys. Chem. Chem. Phys. 2017, 19, 12321-12330.

27. Ziani, A.; Le Paven, C.; Le Gendre, L.; Marlec, F.; Benzerga, R.; Tessier, F.; Cheviré, F.; Hedhili, M. N.; Garcia-Esparza, A. T.; Melissen, S.; Sautet, P.; Le Bahers, T.; Takanabe, K., Photophysical Properties of $\mathrm{SrTaO}_{2} \mathrm{~N}$ Thin Films and Influence of Anion Ordering: A Joint Theoretical and Experimental Investigation. Chem. $\mathrm{Ma}$ ter. 2017, 29, 3989-3998.

28. Kandiel, T. A.; Anjum, D. H.; Sautet, P.; Le Bahers, T.; Takanabe, K., Electronic structure and photocatalytic activity of wurtzite $\mathrm{Cu}-\mathrm{Ga}-\mathrm{S}$ nanocrystals and their $\mathrm{Zn}$ substitution. J. Mater. Chem. A 2015, 3, 8896-8904.

29. Isse, A. A.; Gennaro, A., Absolute potential of the standard hydrogen electrode and the problem of interconversion of potentials in different solvents. J. Phys. Chem. B 2010, 114, 7894-7899.

30. Qureshi, M.; Takanabe, K. Insights on measuring and reporting heterogeneous photocatalysis: efficiency definitions and setup examples. Chem. Mater. 2017, 29, 158-167.

31. Le Bahers, T.; Haller, S.; Le Mercier, T.; Barboux, P., Assessing the Use of BiCuOS for Photovoltaic Application: From DFT to Macroscopic Simulation. J. Phys. Chem. C 2015, 119, 1758517595.

32. Adamo, C.; Barone, V., Toward reliable density functional methods without adjustable parameters: The PBE0 model. J. Chem. Phys. 1999, 110, 6158-6170.

33. R. Dovesi, V. R. S., Roetti, C.; Orlando, R.; ZicovichWilson, C. M.; Pascale, F.; Civalleri, B.; Doll, K.; Harrison, N. M.; Bush, I. J.; D'Arco, P.; Llunell, M.; et al., CRYSTAL14 User's Manual (University of Torino, Torino). 2014.

34. Dovesi, R.; Orlando, R.; Erba, A.; Zicovich-Wilson, C. M.; Civalleri, B.; Casassa, S.; Maschio, L.; Ferrabone, M.; De La Pierre, M.; D'Arco, P.; Noel, Y.; Causa, M.; Rerat, M.; Kirtman, B.,
CRYSTAL14: A Program for the Ab Initio Investigation of Crystalline Solids. Int. J. Quantum Chem. 2014, 114, 1287-1317.

35. Cora, F., The performance of hybrid density functionals in solid state chemistry: the case of $\mathrm{BaTiO}_{3}$. Mol. Phys. 2005, 103, 2483-2496.

36. Mclean, A. D.; Chandler, G. S., Contracted Gaussian-Basis Sets for Molecular Calculations .1. 2nd Row Atoms, $Z=11-18 . J$. Chem. Phys. 1980, 72, 5639-5648.

37. Doll, K.; Harrison, N. M., Chlorine adsorption on the $\mathrm{Cu}(111)$ surface. Chem. Phys. Lett. 2000, 317, 282-289.

38. Weihrich, R.; Anusca, I., Halfantiperovskites II: on the crystal structure of $\mathrm{Pd}_{3} \mathrm{Bi}_{2} \mathrm{~S}_{2}$. Z. Anorg. Allg. Chem. 2006, 632, 335342.

39. Apra, E.; Stefanovich, E.; Dovesi, R.; Roetti, C., An Abinitio Hartree-Fock Study of Silver-Chloride. Chem. Phys. Lett. 1991, 186, 329-335.

40. Noel, Y.; Zicovich-Wilson, C. M.; Civalleri, B.; D'Arco, P.; Dovesi, R., Polarization properties of $\mathrm{ZnO}$ and $\mathrm{BeO}$ : $\mathrm{An}$ ab initio study through the Berry phase and Wannier functions approaches. Phys. Rev. B 2002, 65, 014111.

41. Heyd, J.; Scuseria, G. E.; Ernzerhof, M., Hybrid functionals based on a screened Coulomb potential $(118,8207,2003) . J$. Chem. Phys. 2006, 124, 219906.

42. Heyd, J.; Scuseria, G. E.; Ernzerhof, M., Hybrid functionals based on a screened Coulomb potential. J. Chem. Phys. 2003, 118 , 8207-8215.

43. Marsman, M.; Paier, J.; Stroppa, A.; Kresse, G., Hybrid functionals applied to extended systems. J. Phys.-Condens. Matter 2008, 20, 064201

44. Kresse, G.; Furthmuller, J., Efficiency of ab-initio total energy calculations for metals and semiconductors using a plane-wave basis set. Comp. Mater. Sci. 1996, 6, 15-50.

45. Kresse, G.; Furthmuller, J., Efficient iterative schemes for ab initio total-energy calculations using a plane-wave basis set. Phys. Rev. B 1996, 54, 11169-11186.

46. Kresse, G.; Joubert, D., From ultrasoft pseudopotentials to the projector augmented-wave method. Phys. Rev. B 1999, 59, 17581775.

47. Hobbs, D.; Kresse, G.; Hafner, J., Fully unconstrained noncollinear magnetism within the projector augmented-wave method. Phys. Rev. B 2000, 62, 11556-11570.

48. Chan, G. H.; Deng, B.; Bertoni, M.; Ireland, J. R.; Hersam, M. C.; Mason, T. O.; Van Duyne, R. P.; Ibers, J. A., Syntheses, structures, physical properties, and theoretical studies of $\mathrm{CeM}_{\mathrm{x}} \mathrm{OS}(\mathrm{M}=$ $\mathrm{Cu}, \mathrm{Ag} ; \mathrm{x}$ approximately 0.8 ) and CeAgOS. Inorg. Chem. 2006, 45, 8264-8272.

49. Shannon, R. D., Revised Effective Ionic-Radii and Systematic Studies of Interatomic Distances in Halides and Chalcogenides. Acta Crystallogr. A 1976, 32, 751-767.

50. Cordero, B.; Gomez, V.; Platero-Prats, A. E.; Reves, M.; Echeverria, J.; Cremades, E.; Barragan, F.; Alvarez, S., Covalent radii revisited. Dalton Trans. 2008, 2832-2838.

51. Ollevier, T., Bismuth-Mediated Organic Reactions Preface. Bismuth-Mediated Organic Reactions 2012, 311, Xi-Xii.

52. Ganose, A. M.; Cuff, M.; Butler, K. T.; Walsh, A.; Scanlon, D. O., Interplay of Orbital and Relativistic Effects in Bismuth Oxyhalides: $\mathrm{BiOF}, \mathrm{BiOCl}, \mathrm{BiOBr}$, and $\mathrm{BiOl}$. Chem. Mater. 2016, 28, 1980-1984.

53. Walsh, A.; Payne, D. J.; Egdell, R. G.; Watson, G. W., Stereochemistry of post-transition metal oxides: revision of the classical lone pair model. Chem. Soc. Rev. 2011, 40, 4455-4463.

54. Jin, S.; Chen, X.; Guo, J.; Lei, M.; Lin, J.; Xi, J.; Wang, W.; Wang, W., $\mathrm{Sr}_{2} \mathrm{Mn}_{3} \mathrm{Sb}_{2} \mathrm{O}_{2}$ type oxyselenides: structures, magnetism, and electronic properties of $\mathrm{Sr}_{2} \mathrm{AO}_{2} \mathrm{M}_{2} \mathrm{Se}_{2} \quad(\mathrm{~A}=\mathrm{Co}, \mathrm{Mn}$; $\mathrm{M}=\mathrm{Cu}, \mathrm{Ag})$. Inorg. Chem. 2012, 5l, 10185-10192.

55. Tsuji, I.; Shimodaira, Y.; Kato, H.; Kobayashi, H.; Kudo, A., Novel Stannite-type Complex Sulfide Photocatalysts $\mathrm{A}_{2}(\mathrm{I})-\mathrm{Zn}$ $\mathrm{A}(\mathrm{IV})-\mathrm{S}_{4}(\mathrm{~A}(\mathrm{I})=\mathrm{Cu}$ and $\mathrm{Ag} ; \mathrm{A}(\mathrm{IV})=\mathrm{Sn}$ and $\mathrm{Ge})$ for Hydrogen Evolution under Visible-Light Irradiation. Chem. Mater. 2010, 22, 1402-1409. 
56. Suzuki, T.; Hisatomi, T.; Teramura, K.; Shimodaira, Y.; Kobayashi, H.; Domen, K., A titanium-based oxysulfide photocatalyst: $\mathrm{La}_{5} \mathrm{Ti}_{2} \mathrm{MS}_{5} \mathrm{O}_{7}(\mathrm{M}=\mathrm{Ag}, \mathrm{Cu})$ for water reduction and oxidation. Phys. Chem. Chem. Phys. 2012, 14, 15475-15481. 


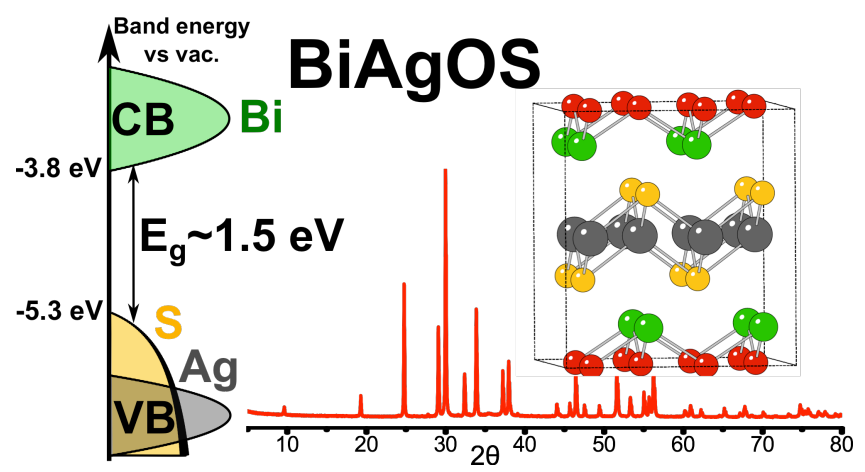

